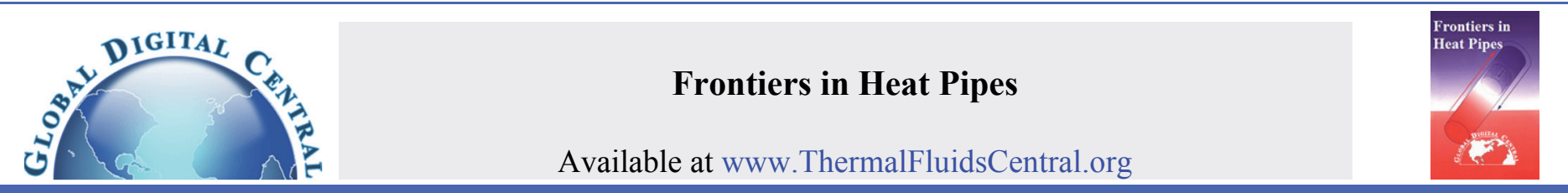

\title{
THERMAL TESTS AND TWO-PHASE PHENOMENA OBSERVATIONS IN A TRANSPARENT EXPERIMENTAL LOOP HEAT PIPE
}

\author{
Benjamin Siedel, Nathanaël Rivière, Valérie Sartre*, Frédéric Lefèvre \\ University of Lyon, CNRS, INSA-Lyon, Université Claude Bernard Lyon 1, CETHIL UMR5008, F-69621, Villeurbanne, France
}

\begin{abstract}
An experimental setup has been designed, assembled and instrumented to perform thermal tests and observations inside a loop heat pipe (LHP). The hysteresis and temperature oscillations phenomena are investigated. The influence of nucleate boiling in the reservoir on the LHP operation and the effect of non-condensable gases are assessed. The links between temperature oscillations and the hydrodynamic behaviour of the LHP are highlighted. Finally, observations through the transparent lines confirm the occurrence of the condensation phenomena in the condenser and in the transport lines that were already observed by other author.
\end{abstract}

Keywords: transparent materials; oscillations; boiling; condensation; hysteresis

\section{INTRODUCTION}

Loop Heat Pipes (LHPs) are efficient heat transfer devices based on the passive heat transfer between a heat source and a heat sink, using the capillary pressure to circulate the fluid. Compared to conventional heat pipes, LHPs offer several advantages in terms of flexibility, operation against gravity and heat transport capability. As a consequence, many experimental works have been devoted to the understanding of physical mechanisms governing these systems in various operating conditions and to the optimization of their design. Despite its simplicity, various undesirable LHP behaviours have been experimentally observed after start-up or consequently to the change of power or heat sink temperature, like hysteresis phenomena and oscillations.

Wolf and Bienert (1994) report a vapour temperature hysteresis at low power and with a large positive elevation (evaporator above the condenser). However, the authors do not provide any explanation regarding this phenomenon. Low power hysteresis effects have also been observed by Cheung et al. (1998). The authors hypothesise that the loop steady state temperatures can be shifted due to two-phase dynamics in the evaporator core that influence the parasitic heat fluxes. Indeed, a steep power decrease leads to a sudden recession of the meniscus in the condenser and changes the distribution of liquid and vapour inside the evaporator core and the bayonet. Ku (1999) also describes another hysteresis phenomenon, which occurs between two consecutive tests. If the vapour partially invades the wick during the first test, there might be entrapment of vapour zones inside the capillary structure. During the second test, the LHP then operates at a higher temperature. Vershinin and Maydanik (2007) conduct an extensive analysis of hysteresis phenomena in LHPs. They report three types of hysteresis effects, all of them being connected to the redistribution of liquid between the compensation chamber and the condenser in case of change of heat load. The first type is induced by a capillary hysteresis. The evaporation front may change and moves into the wick at very low heat loads or at high heat loads, inducing heat-exchange and temperature hysteresis. The second type is connected to the change between a partially filled and a hard-filled reservoir, while the third one is a consequence of the initial distribution of liquid in the LHP.

The understanding of the origin of temperature oscillations in LHPs and of operating conditions, which cause them, is another challenging issue. As explained by Launay and Vallée (2011), three types of temperature oscillation regimes have been reported in the literature: (i) ultra-high frequency temperature oscillations (period less than 1s), caused by the formation of liquid slugs in the condenser or the vapour line, (ii) high frequency low amplitude oscillations (period of few seconds or few minutes) caused by the inability of the vapour front to find a stable position inside the condenser, and (iii) low frequency high temperature oscillations (period of few hours), which may appear in case of large evaporator thermal inertia, low heat loads and cold sink temperatures. In many experimental studies, these temperature oscillations are recorded using non-intrusive thermocouples implemented along the LHP wall. Very few investigations provide direct observation of the hydrodynamic phenomena causing oscillations of types (i) and (ii).

In this work, a research-oriented apparatus is developed to provide key elements on the understanding of the thermal and hydraulic phenomena occurring in LHPs. The goal of the proposed experiment is to provide a set of experimental data - including temperature and pressure measurements at different locations of the LHP - that are needed to validate numerical and analytical models presented in the literature (Siedel et al., 2015a), but also observations of the fluid location inside the system to better understand some behaviours of the LHP system observed in the literature. Indeed, some parameters of LHP models (Siedel et al., 2013, Siedel et al., 2015b) are difficult to estimate (thermal contact resistance between the heated wall of the evaporator and the wick structure, effective thermal conductivity of the porous material of the wick, accommodation coefficient at the evaporation interface) and need to be better studied experimentally. Therefore, the setup has been

*Corresponding author. Email: valerie.sartre@insa-lyon.fr 
designed to be as modular as possible: the various components (transport lines, porous structure, vapour groove block, etc.) are interchangeable in order to perform experimental parameter analyses with various fluids and porous wicks, which will be specifically fabricated for LHP applications in a future work. Several components of the device are transparent to enable a better understanding of the phenomena involved in the loop. Up to now, very few LHP test benches presented in the literature allow visual observation of the fluid flows (Launay and Mekni, 2010, Bartuli et al., 2013, D'Entremont and Ochterbeck, 2009, Mottet et al., 2015, Kaled, 2013). Launay and Mekni, (2010) fabricated a two-dimensional transparent LHP to perform infrared temperature measurements of the evaporator. Mottet et al. (2015) proposed a two-dimensional micromodel of the unit cell of a capillary evaporator, in order to perform visualization of the invasion of the wick by vapour. Bartuli et al. (2013) studied a flat LHP condenser which upper face is made of glass, allowing visual observations, photography and video recording of the process of condensation. Kaled (2013) presented an experimental test bench of a CPL specifically developed for terrestrial applications, where the tubular condenser is designed with glass, allowing observation of the dynamics of phase distribution and evolution of the condensation regimes. In this paper, we present a first set of experimental data and show the influence of several parameters (non-condensable gases (NCGs), boiling in the reservoir) on the steady-state operation of the system and on the hysteresis that is observed. Furthermore, the two-phase phenomena causing the temperature oscillations are recorded using high speed videography and analysed. The results are systematically compared to other works of the literature to gain some knowledge on the behaviour of the LHP device.

\section{EXPERIMENTAL SET-UP}

\subsection{Description of the apparatus}

Figures 1 and 2 present a global view of the experimental set-up. The evaporator/reservoir structure (Fig. 3) is a stack of disk-shaped elements. Its casing is made of polyether ether ketone, an organic polymer with a thermal conductivity approximately equal to $0.25 \mathrm{~W} \cdot \mathrm{m}^{-1} \cdot \mathrm{K}^{-1}$. Such a material prevents the longitudinal parasitic heat losses through the casing while maintaining a good mechanical integrity for the entire operating temperature range, i.e. $20-100{ }^{\circ} \mathrm{C}$. The reservoir, with a diameter of 38 $\mathrm{mm}$ and a height equal to $30 \mathrm{~mm}$ is located in the upper part. The entry of the liquid flowing from the condenser, of inner diameter $8 \mathrm{~mm}$, is situated on its side. A borosilicate glass window is mounted at the top for a direct view of the reservoir inner part. A sintered nickel porous metal disk, of diameter $40 \mathrm{~mm}$ and thickness $6 \mathrm{~mm}$ is inserted between the copper block and the reservoir. The measured porosity is rather low and equal to $34 \%$ and the pore diameter is approximately equal to $10 \mu \mathrm{m}$. The vapour grooves, $2 \mathrm{~mm}$ wide and $1.5 \mathrm{~mm}$ deep, are engraved in an 8 $\mathrm{mm}$ thick copper block which provides a uniform heat distribution to the wick. Heat is provided by a flat circular Kapton ${ }^{\circledR}$ polyamide heater (38.1 $\mathrm{mm}$ diameter, $50 \mu \mathrm{m}$ thick) in contact with this block. A vapour channel of inner diameter $8 \mathrm{~mm}$ enables the exit of the vapour on the side of the evaporator.

The condenser and the vapour and liquid lines are glass tubes with an internal diameter of $2 \mathrm{~mm}$ and a wall thickness of $2 \mathrm{~mm}$. The vapour line is $685 \mathrm{~mm}$ long whereas the liquid line length is equal to $245 \mathrm{~mm}$. The height difference between the liquid and vapour lines is of $30 \mathrm{~mm}$. The water cooled condenser, which acts as a heat sink, is a $250 \mathrm{~mm}$ long parallel-flow tube-in-tube heat exchanger, with an external diameter equal to $26 \mathrm{~mm}$. It has been pre-designed to enable the test of the LHP in various operating modes (variable and fixed conductance) for heat loads up to at least $30 \mathrm{~W}$. The heat sink temperature at the condenser inlet, $T_{\text {sink, }}$, is thermoregulated using a thermostatic bath.

A filling apparatus has been designed to provide a correct degassing and filling of the loop heat pipe (Fig. 1). It consists of a reservoir including a heating device, which is connected to the compensation chamber.

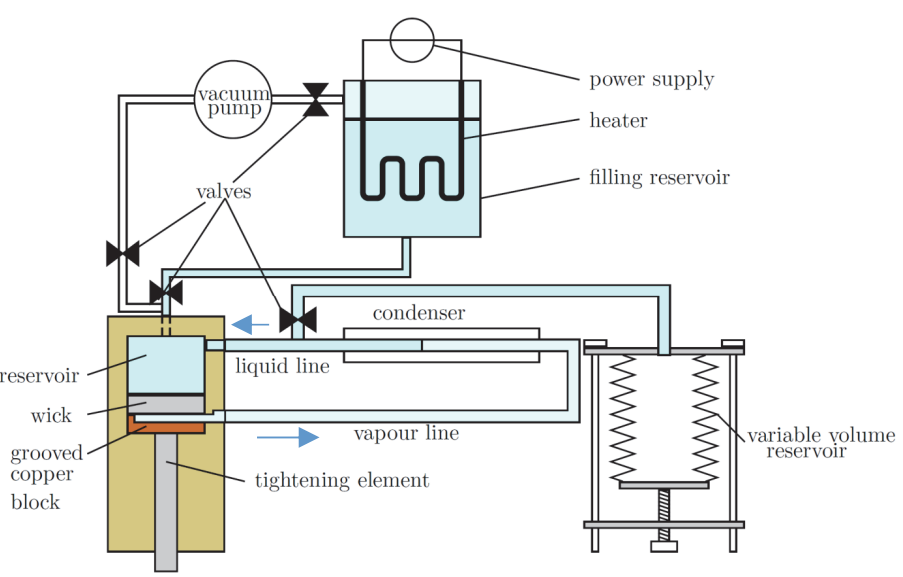

Fig. 1 Schematic of the experimental set-up

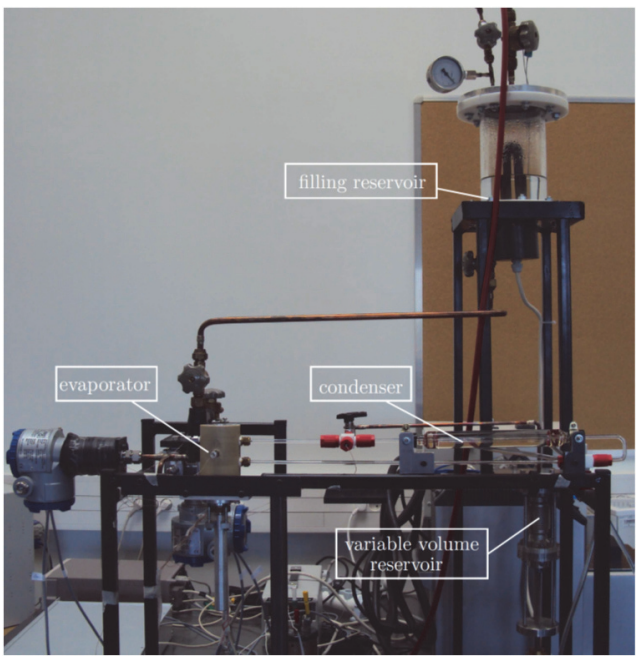

Fig. 2 Photo of the experimental set-up

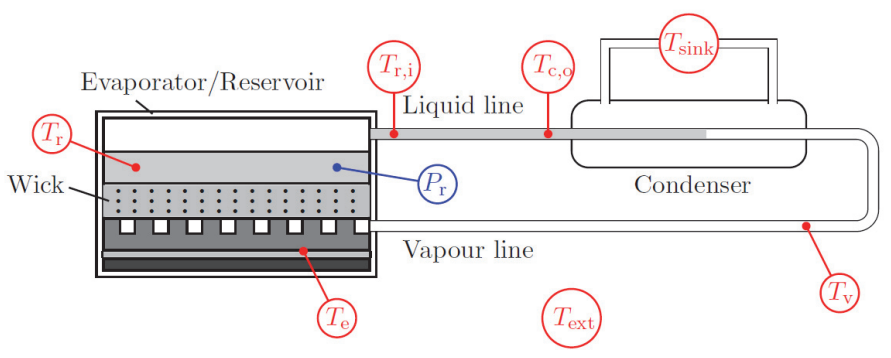

Fig. 3 Location of the thermocouples and pressure sensors

\subsection{Instrumentation}

Several K-Type thermocouples ( $80 \mu \mathrm{m}$ in diameter) are inserted inside the experimental setup to provide information on the thermal state of the device (Fig. 2). The uncertainty of each temperature measurement, after calibration, is estimated to $\pm 0.2 \mathrm{~K} . T_{e}, T_{r}, T_{v}, T_{c, o}$ and $T_{r, i}$ are the mean temperature of the copper block close to the heater, of the liquid bulk in the reservoir, of the vapour, of the liquid exiting the condenser and of the liquid entering the reservoir, respectively. Since a large temperature difference may exist between the tube wall and the fluid, particularly in the vapour line, two PTFE connectors enable the insertion of the thermocouples $T_{v}$ and $T_{c, o}$ inside the tube, and $T_{r, i}$ is inserted through the reservoir (from its opposite side) in the liquid line. The heat sink temperature $T_{\text {sink }}$ is given by the thermoregulation unit and the ambient temperature Text is measured by a PT100 sensor. An absolute pressure sensor (accuracy $\pm 187 \mathrm{~Pa}$ at 2.5 bars) is also mounted on the reservoir to estimate the amount of non-condensable gases in the LHP. 
A four-wire circuit is used to accurately measure the heat dissipated by the heater. The largest part of this heat, Qin is conducted through the copper block and dissipated by the LHP. The remainder part is conducted through the casing, then lost to the ambient and does not participate to the LHP operation. A heat flux sensor is located at the back side of the heater to estimate heat losses. The heat load dissipated by the LHP is then measured with an accuracy of $\pm 0.03 \mathrm{~W}$.

To provide an accurate slow motion analysis of the fluid flow inside the tubes, a high-speed digital camera is used, with an acquisition frequency ranging from $50 \mathrm{fps}$ to $500 \mathrm{fps}$, depending of the mechanisms that are studied.

\subsection{Experimental procedure}

The filling reservoir is evacuated using a vacuum pump before being filled with the working fluid. The system is heated for several hours and periodically degassed using the vacuum pump. The entire loop heat pipe is also evacuated. The valve between the loop and the filling apparatus is then opened and the filling of the LHP with liquid is ensured using gravity forces. During this procedure, the filling ratio of the reservoir is monitored by a direct observation through the glass window. The amount of NCGs in the LHP is estimated by comparing the pressure in the reservoir with the saturation pressure associated with the reservoir temperature. In this paper, the LHP is always filled with water. This fluid is highly sensitive to NCGs at temperatures closed to the ambient temperature.

For the following tests, the heating resistance is supplied with a given electrical power. All LHP temperatures are then recorded using the acquisition system. When all the temperatures are stabilized in time, the steady-state is considered to be reached. A new electrical power step is then applied to the system, and the same procedure is repeated until the maximum allowable temperature is reached at the evaporator wall (a security automatically switches off the power supply). For the hysteresis tests, the power is increased stepwise and then decreased stepwise too.

\section{STEADY-STATE OPERATION}

\subsection{Evolution of the LHP temperature with the heat load}

Figure 4 presents the main temperatures as a function of the heat load at $T_{\text {sink }}=20^{\circ} \mathrm{C}$. The transition between the variable and the constant conductance modes ranges from $40 \mathrm{~W}$ to $45 \mathrm{~W}$. The difference between $T_{e}$ and $T_{r}$ increases with the heat load for the entire tested range, but particularly at very low heat loads and in constant conductance mode. This difference is mainly due to the thermal contact resistance between the evaporator copper block and the porous wick. The difference between the vapour temperature and the temperature inside the reservoir is dependent on the pressure losses inside the transport lines and the NCGs in the reservoir. In this test, the amount of NCGs is constant and equal to 15 mbars. Even if this value is small, it is nonetheless significant compared to the saturation pressure of water at this temperature. Therefore, the partial pressure of NCGs induces a rather significant difference between $T_{v}$ and $T_{r}$. In section 3.3, some results without NCGs are presented that show that the difference between $T_{v}$ and $T_{r}$ is negligible.

\subsection{Hysteresis phenomena}

Major hysteresis phenomena have been observed in the present study, as shown for instance in Figure 5 for a power cycle with a heat sink temperature of $20{ }^{\circ} \mathrm{C}$, an ambient temperature ranging from $21.6^{\circ} \mathrm{C}$ to $23.9^{\circ} \mathrm{C}$ and a partial pressure of NCGs equal to 150 mbars. A significant difference is observed between operating curves at increasing and decreasing heat fluxes. Measurements are not presented for $T_{v}$ at very low heat loads because the thermocouple is in contact with subcooled liquid due to the recession of the meniscus inside the vapour line.

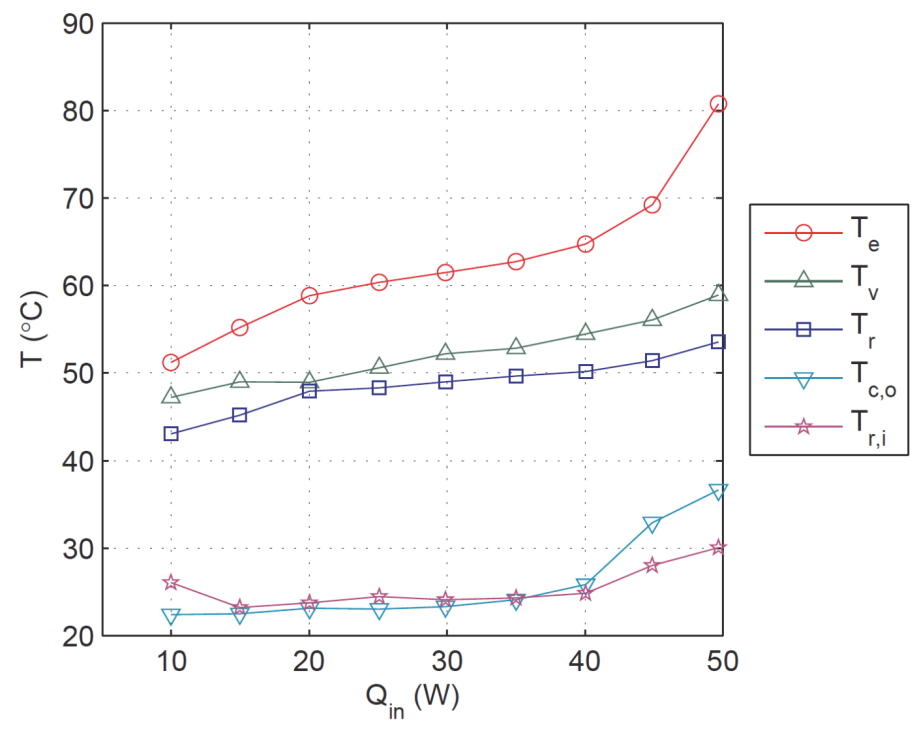

Fig. 4 LHP temperatures as a function of the heat input $\left(P_{N C G}=\right.$ 150 mbars; $T_{\operatorname{sink}}=20^{\circ} \mathrm{C}$ )

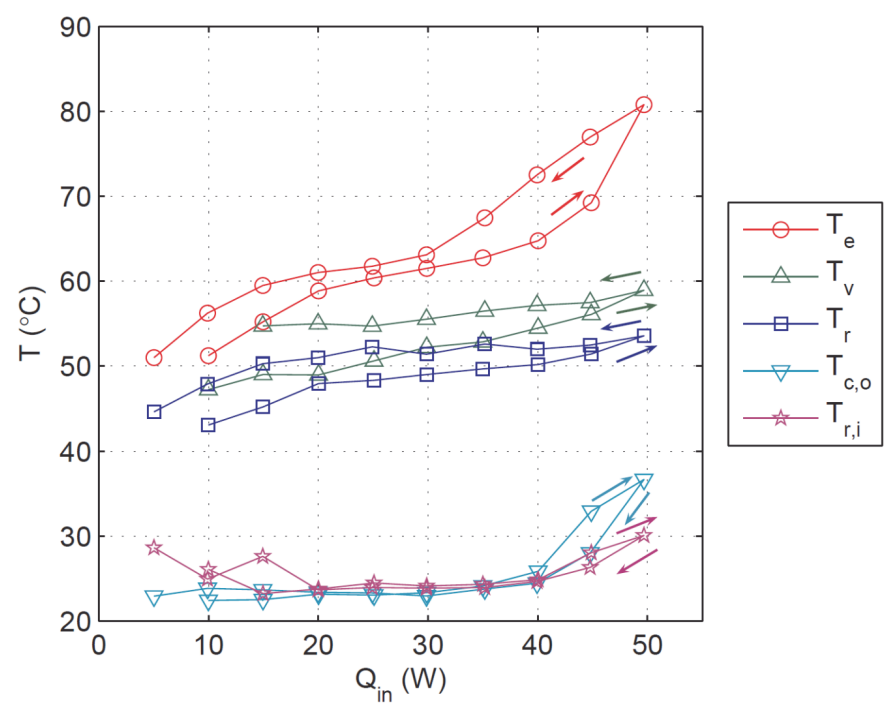

Fig. 5 Temperature hysteresis $\left(P_{N C G}=150\right.$ mbars; $\left.T_{\operatorname{sink}}=20^{\circ} \mathrm{C}\right)$

The observed hysteresis cannot be explained by the presence of NCGs. Indeed, desorption of NCGs trapped in the system or due to heat leaks would lead to a higher operating temperature. However, in this test, no significant increase of NCGs has been observed neither on the pressure measurement nor on the difference between $T_{v}$ and $T_{r}$ (Fig. 5).

The location of the liquid inside the system does also not explain this hysteresis. Indeed, no significant change of the filling level of the reservoir is reported and the initial state of the LHP prior to start-up cannot be the source of the hysteresis. Figure 5 shows that above $35 \mathrm{~W}$, the evaporator thermal resistance, linked to the temperature difference $\left(T_{e}-T_{v}\right)$ increases with the heat flux, and so does the parasitic heat flux, proportional to $\left(T_{e}-T_{r}\right)$. This degradation of the heat transfer at the evaporator may be due to the development of vapour pockets (dried zones) at the contact zones between the evaporator wall and the porous wick, as described by Louriou (2010). The displacement of the liquidvapour front inside the porous structure may increase the transversal parasitic heat flux, thus leading to an increase of the operating temperature. For the same heat flux (above $35 \mathrm{~W}$ ), the evaporator thermal resistance is higher at decreasing heat flux than at increasing heat flux (higher $T_{e}-T_{v}$ ). Therefore, we assume that the hysteresis could be due to the evaporation zone and may correspond to the capillary hysteresis observed by Vershinin and Maydanik (2007). The development of a vapour region inside the capillary structure and its recession when 
decreasing the heat load (imbibition) may lead to a significant hysteresis, as it was presented in the numerical investigation of Louriou (2010).

\subsection{Nucleate boiling in the reservoir}

Nucleate boiling is observed in the reservoir in particular operating conditions. It occurs at moderate to high heat loads and this phenomenon is delayed when the amount of NCGs increases. Figure 6 presents the same experimental test as in Figure 4, but without NCGs. In that case, the difference between $T_{v}$ and $T_{r}$ is negligible, which shows that the pressure drop inside the transport lines is negligible. When the heat load increases from $10 \mathrm{~W}$ to $30 \mathrm{~W}$, heat transfer between the wick and the liquid bulk in the reservoir is mainly convective, as in Figure 4. Nevertheless, when the heat load reaches $35 \mathrm{~W}$, boiling incipience occurs at the surface of the capillary structure and leads to larger heat exchange inside the reservoir. Such an enhanced heat transfer at the surface of the wick increases the parasitic heat flux. As a consequence, $T_{r}$ and $T_{v}$ slightly increase. The major change, however, is observed for $T_{e}$. The evaporator temperature increases abruptly after the boiling incipience.

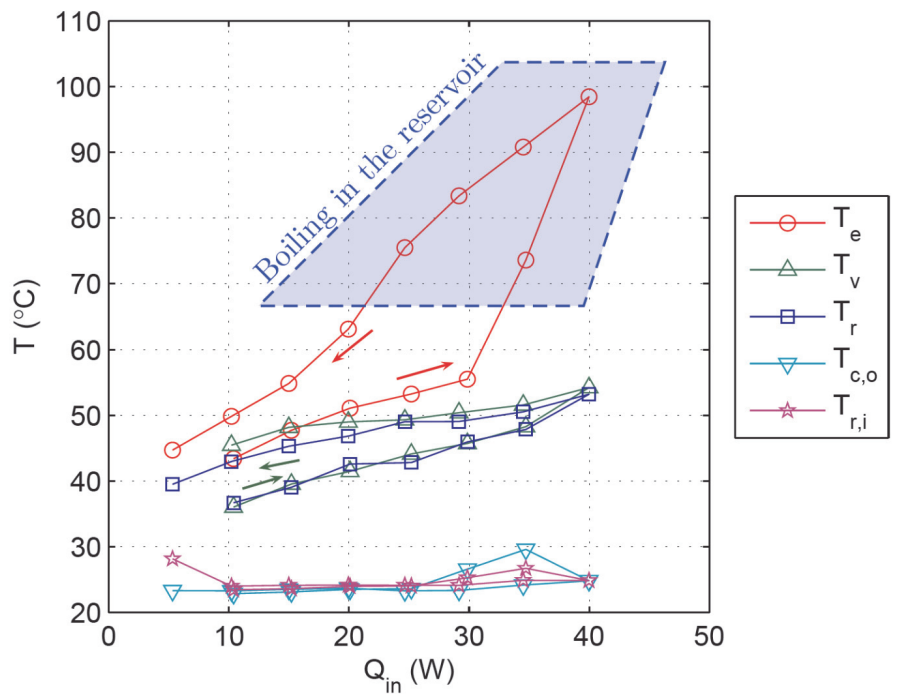

Fig. 6 Consequences of the boiling phenomena in the reservoir on the temperatures of the LHP (no NCGs; $T_{\text {sink }}=20^{\circ} \mathrm{C}$ )

When the heat load decreases, boiling remains inside the reservoir until $Q_{i n}=20 \mathrm{~W}$. This is the well-known boiling hysteresis: a superheat is necessary to initiate the nucleation process at the surface of the wick, but this superheat is not necessary to keep the nucleation sites active. This boiling hysteresis effect accentuates the capillary hysteresis that has been previously observed.

The prediction and the prevention of boiling incipience in the reservoir are of major interest, given the consequences on the evaporator temperature. However, the nucleation depends on many parameters and an accurate prediction of the phenomenon is, as such, not available. The following parameters may have a significant influence on the nucleation:

- The nucleation superheat is inversely proportional to the radius of the nucleation site. Therefore, smaller pores in the capillary structure lead to a higher superheat for boiling at the surface of the wick. Likewise, a clean reservoir without impurities and smooth contacts between the wick, the evaporator envelope and an eventual seal also prevent the nucleation.

- The nucleation is also dependent on the surface tension, the density and the latent heat of vaporisation of the fluid. Thus, the nature of the working fluid and the operating temperature have a significant influence on the boiling incipience.

- Heat that is dissipated at the wick surface in the reservoir corresponds to the transversal parasitic heat flux which depends on the geometrical and thermo-physical properties of the wick. Therefore, nucleation can be avoided by optimizing the properties of the wick, especially by decreasing the effective thermal conductivity of the wick, which is probably high in this experiment due to its low porosity.

- The level of liquid inside the reservoir may change the homogeneity of the liquid bulk and the development of convective cells in it. Therefore, the amount of working fluid in the system can also modify the boiling incipience.

- The presence of NCGs may strongly modify the occurrence of boiling in the reservoir. This is further detailed in subsection 3.4 .

\subsection{Influence of the NCGs on the steady-state behaviour}

Figure 7 shows the comparison of the LHP temperatures without NCGs and with an amount of NCGs corresponding to a partial pressure of 30 mbars. This additional pressure $P_{N C G}$ leads to a higher temperature difference between $T_{v}$ and $T_{r}$. As a consequence, the parasitic heat transfer through the wick is larger and the operating temperature is higher. As the operating temperature increases, $P_{N C G}$ remains almost constant because the gas density does not vary much and the volume occupied in the reservoir is almost constant. However, the pressure inside the system increases significantly with the increase of the operating temperature, inducing a lower influence of the NCGs.

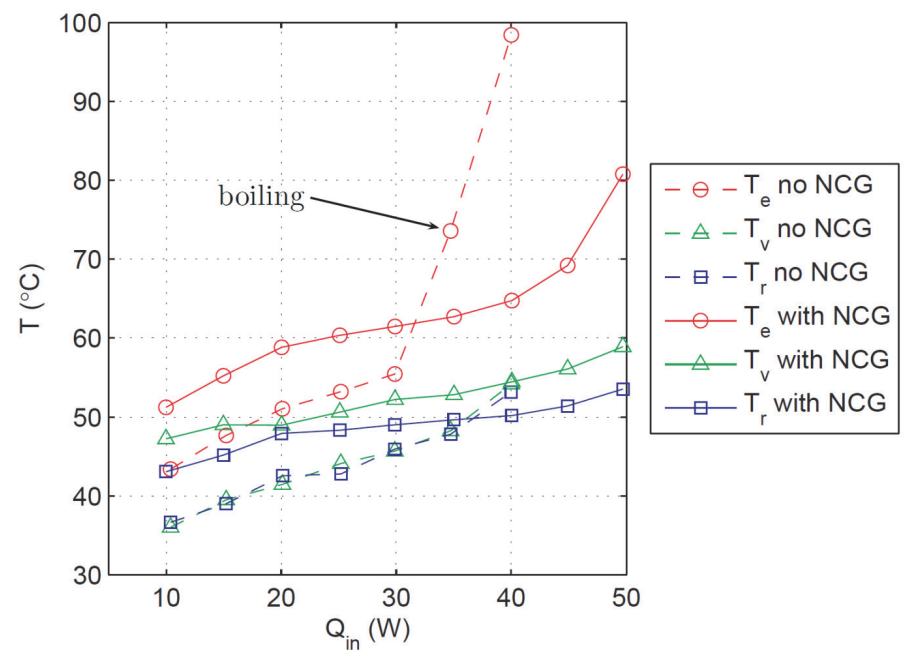

Fig 7 Influence of the NCGs on the LHP temperatures at increasing heat load $\left(T_{\sin k}=20^{\circ} \mathrm{C}\right)$

When the heat load exceeds $30 \mathrm{~W}$, a major difference is observed between both configurations. As explained before, the evaporator temperature of the LHP without NCGs sharply increases due to boiling occurrence in the reservoir. When NCGs are present in the reservoir, the nucleation temperature in the reservoir is higher and boiling is not observed. The LHP can thus operate at higher heat loads and reaches the variable conductance mode at $Q_{i n} \approx 45 \mathrm{~W}$.

In case of pool boiling, the temperature required to initiate the nucleation $T_{n u c}$ is equal to:

$T_{n u c}=T_{\text {sat }}\left(P_{r}+P_{\text {static }}\right)+\Delta T_{\text {nuc }}$

where $\Delta T_{n u c}$ is the nucleation superheat, depending on the operating conditions, the nature of the fluid and the material as well as the roughness of the surface. $P_{\text {static }}$ is the hydrostatic pressure induced by the height of liquid above the surface.

NCGs can have opposite effects on the nucleation phenomena:

- NCGs in the reservoir lead to a larger pressure difference between the vapour in the grooves and the reservoir. Consequently, the temperature difference also increases and 
larger parasitic heat fluxes are expected towards the reservoir, which may increase the probability of boiling incipience.

- Gases dissolved in the fluid as well as gas entrapment at the surface of the porous structure tend to increase the boiling phenomena (Rainey et al., 2003). As explained by Carey (1992), both entrapped gas in surface cavities and dissolved gas facilitate the initial nucleation process, lowering the superheat required to initiate the nucleation. The entrapment of gas in the wick depends on the history of the LHP operation. Therefore, the presence of preferential nucleation sites at the surface of the capillary structure may vary for several consecutive tests. An extensive discussion regarding heterogeneous nucleation can be found in Carey (1992).

- $\quad$ On the contrary, the gas present above the free surface inside the reservoir induces a partial pressure $P_{N C G}$, which increases the nucleation temperature:

$T_{n u c}=T_{\text {sat }}\left(P_{r}+P_{\text {static }}\right)+\Delta T_{n u c}+\frac{\partial T_{\text {sat }}}{\partial P_{\text {sat }}} P_{N G C}$

The last term depends on both the amount of NCGs, the nature of the fluid and the experimental conditions. In the case of water at low temperature, $\frac{\partial T_{s a t}}{\partial P_{s a t}}$ is significant and induces a large effect of the partial pressure of NCGs. For instance, if the saturation temperature is equal to $45^{\circ} \mathrm{C}$, a partial pressure of the NCGS of $3000 \mathrm{~Pa}$ leads to an additional superheat of $5.4 \mathrm{~K}$. The nucleation phenomenon can therefore be delayed due to the NCGs. This effect was experimentally observed in loop thermosyphons by He et al. (2013).

According to the experimental results, the third mentioned effect has the largest influence on the LHP behaviour in the present case. Although NCGs induce a higher operating temperature, particularly at low heat loads, they prevent the LHP from a degraded operation mode due to boiling in the reservoir. Therefore, the system performance is maintained at high heat loads and the maximal heat load that can be reached by the LHP increases.

\section{OSCILLATING PHENOMENA}

Temperature oscillations are observed at start-up with a heat load equal to $5 \mathrm{~W}$ and a heat sink temperature of $20^{\circ} \mathrm{C}$ (Fig. 8), and also at moderate heat loads $(20 \mathrm{~W})$ and $T_{\text {sink }}-T_{a m b} \sim 10 \mathrm{~K}$. Three types of oscillations are observed:

- $\quad$ high amplitude and low frequency oscillations for $T_{v}(6 \mathrm{~K})$ and $T_{r, i}(2.5 \mathrm{~K})$

- $\quad$ low amplitude and low frequency oscillations for $T_{e}$ and $T_{c, o}(<$ $1 \mathrm{~K})$.

- $\quad$ high frequency and low amplitude oscillations for $T_{r}(<1 \mathrm{~K})$.

The two first mentioned oscillations are a consequence of the condensation regime in the vapour line and the intermittent flow of liquid in it. For $T_{e}$, a damping effect due to the large thermal inertia of the copper block explains lower amplitude of the oscillations. The third mentioned oscillation is due to the location of the thermocouple inside the reservoir, close to the wick. Temperature gradients as well as convection phenomena exist in the liquid bulk, resulting in variations of the measured temperature as it was previously explained.

The observations through the transparent vapour line enable to relate the temperature oscillations to the hydrodynamic mechanisms in the tube. At such a very low heat load, the vapour condenses completely inside the vapour line. At the point A (figure 7), the meniscus is located downstream of the thermocouple measuring $T_{v}$. Therefore, the thermocouple measures the temperature of the vapour coming from the evaporator, close to the saturation temperature. From the point $\mathrm{A}$ to the point $\mathrm{C}$, the meniscus slowly moves towards the evaporator. The mass flow rate inside the tubes being very low, the influence of the reservoir temperature on $T_{r, i}$ is large and a continuous increase of $T_{r, i}$ is observed at the same time. Between points $\mathrm{A}$ and $\mathrm{C}, T_{v}$ is first approximately constant until the meniscus reaches the thermocouple (point B) and recedes upstream of the temperature sensor $T_{v}$. Therefore, the thermocouple measures the temperature of subcooled liquid, so $T_{v}$ gradually decreases. Simultaneously, condensation occurs inside the vapour line as a consequence of heat losses to the ambient. Droplets grow on the internal wall of the vapour line while vapour still flows in the central part of the tube. As their size increases, the droplets coalesce. At the point $\mathrm{C}$, the coalescence of large droplets leads to the formation of a liquid slug. This slug is then pushed downstream by the vapour, dragging along the liquid attached on the internal wall. As a consequence, the meniscus moves downstream of the thermocouple, $T_{v}$ suddenly increases and the temporary increase of the mass flow rate brings subcooled liquid to the liquid line, thus inducing a sharp decrease of $T_{c, o}$ and $T_{r, i}$.

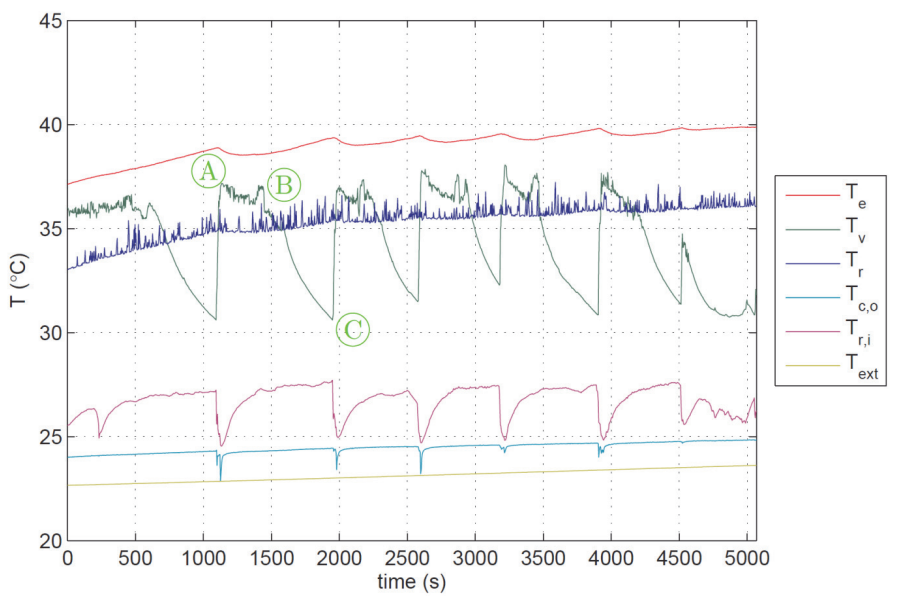

Fig 8 Oscillations during a start-up at $5 \mathrm{~W}\left(T_{\sin k}=20^{\circ} \mathrm{C}\right)$

\section{FLOW OBSERVATIONS IN THE VAPOUR LINE AND IN THE CONDENSER}

\subsection{Condensation in the condenser}

Figure 9 shows the flow regimes that can be seen inside the condenser. As presented in the figure, several zones can be determined. Upstream, a long annular zone is observed, governed by capillary forces. A slight asymmetry due to the gravity is seen, with a thicker liquid film on the bottom of the tube than in the upper part. An almost hemispherical meniscus is present at the end of the annular region, followed by a train of bubbles. Further downstream, several uncondensed isolated bubbles are observed.

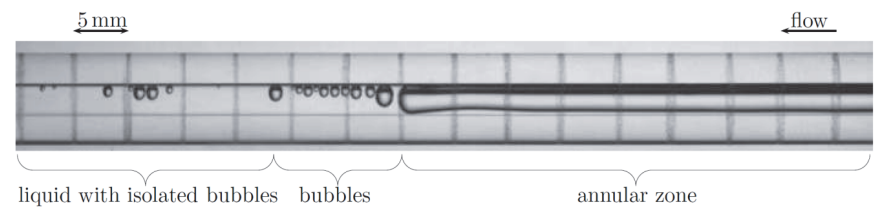

Fig 9 Condensation regimes in the condenser $-Q_{\text {in }}=24 \mathrm{~W}, T_{\operatorname{sink}}=$ $10{ }^{\circ} \mathrm{C}$

A similar flow structure has already been reported in the literature in the case of condensation in minichannels (Méderic et al., 2004, Méderic et al., 2005, Louahlia-Gualous and Mecheri, 2007). Médéric et al. (2004) compared the flow characteristics of $n$-pentane condensing in straight smooth tubes with 3 distinct internal diameters: $10 \mathrm{~mm}, 1.1 \mathrm{~mm}$ and $0.56 \mathrm{~mm}$. For the tube of $1.1 \mathrm{~mm}$ inner diameter the hydraulic diameter was close to the capillary length defined as:

$L_{c a p}=\left(\frac{\sigma}{\left(\rho_{l}-\rho_{v}\right) g}\right)^{\frac{1}{2}}$ 
where $\sigma$ is the surface tension of the working fluid. In that case, gravity and capillary forces are in competition and the stratification phenomenon is weak. The authors observed interfacial instabilities due to the difference of velocity between the vapour and the liquid phases. The increase of the amplitude of these waves lead to the formation of a liquid slug and to the release of a Taylor bubble. The elongated bubble formed was quickly transformed into a spherical one.

In the present study, the same phenomena are observed, as shown in Fig. 10. The capillary length of water between $0{ }^{\circ} \mathrm{C}$ and $100{ }^{\circ} \mathrm{C}$ ranges from $2.4 \mathrm{~mm}$ to $2.8 \mathrm{~mm}$. The internal diameter of the tubes is slightly lower than this value, leading to a major contribution of the capillary forces on the equilibrium between both phases.

The figure shows the minor stratification of the annular upstream flow regime. On the bottom of the tube, the liquid-vapour interface is wavy. The quasi-hemispherical meniscus moves forward, leading to the potential coalescence of isolated bubbles, as seen at $t=234 \mathrm{~ms}$, or to the coalescence of an isolated bubble with the annular wavy region $(t=$ $390 \mathrm{~ms}$ ). At $t=460 \mathrm{~ms}$, the amplitude of the wave increases substantially. At $t=480 \mathrm{~ms}$, the upper part of the interface is also deformed, leading to an eventual detachment of an elongated bubble at $t=484 \mathrm{~ms}$. This liquid slug, formed between the two vapour regions, moves rapidly downstream while the newly detached elongated bubble condenses. This fast phenomenon induces a large deformation of the bubble and of the meniscus at the end of the annular zone. At $t=532 \mathrm{~ms}$, the bubble is almost spherical and located in the upper part of the tube, due to the buoyancy.

Figure 11 shows the movement of the hemispherical meniscus inside the condenser during a period of $4.8 \mathrm{~s}$. The location of the meniscus varies of about $15 \mathrm{~mm}$ between $t=0.8 \mathrm{~s}$ and $t=4 \mathrm{~s}$. This back and forth movement inside the condenser and the presence of isolated bubbles downstream show the difficulty to determine a clear two-phase length inside the condenser. According to El Achkar et al. (2012), the latent heat dissipated in the isolated bubbles zone is negligible in comparison to the annular and the intermittent zone. Furthermore, these authors state that $80 \%$ to $90 \%$ of the heat transfer in the isolated bubble zone is attributed to sensible heat. This is confirmed by the present observations. Indeed, Fig. 11 presents no significant variation of the volume of the isolated bubbles. This shows that phase-change is not a major heat transfer mechanism in the isolated bubbles region. Therefore, in a modelling stage of the heat transfer inside the condensation zone, this region can be considered as single-phase with an acceptable approximation. Thus, the two-phase length inside the condenser must correspond to the average location of the meniscus at the end of the annular zone.

\subsection{Dropwise condensation in the vapour line}

Figure 12 presents a view of the vapour line during operation at $Q_{\text {in }}=$ $27 \mathrm{~W}$. Despite the thickness of the tube $(2 \mathrm{~mm})$ and the low thermal conductivity of glass $\left(1 \mathrm{~W} \cdot \mathrm{m}^{-1} \cdot \mathrm{K}^{-1}\right)$, heat losses to the ambient lead to the condensation of the vapour flowing through the transport line. This phenomenon is observed in the entire length of the vapour line, whatever the heat load.

As presented in the figure, drop-wise condensation occurs in the vapour line. When condensation occurs on a surface, the form of condensation, film-wise or drop-wise, is dependent of the wettability of the surface (Collier, 1994). In the present case, water is the working fluid, and the internal surface of the tube is smooth glass. Such a configuration corresponds to a mildly hydrophobic condition (Birdi et al., 1989) that enables drop-wise phase change. In other experimental conditions, the mode of condensation could differ, depending on the working fluid, the material, the surface roughness and the operating temperature. For example, the contact angle of water on a polished surface of copper at low pressure is low (Bernardin et al., 1997) and could lead to film-wise condensation.
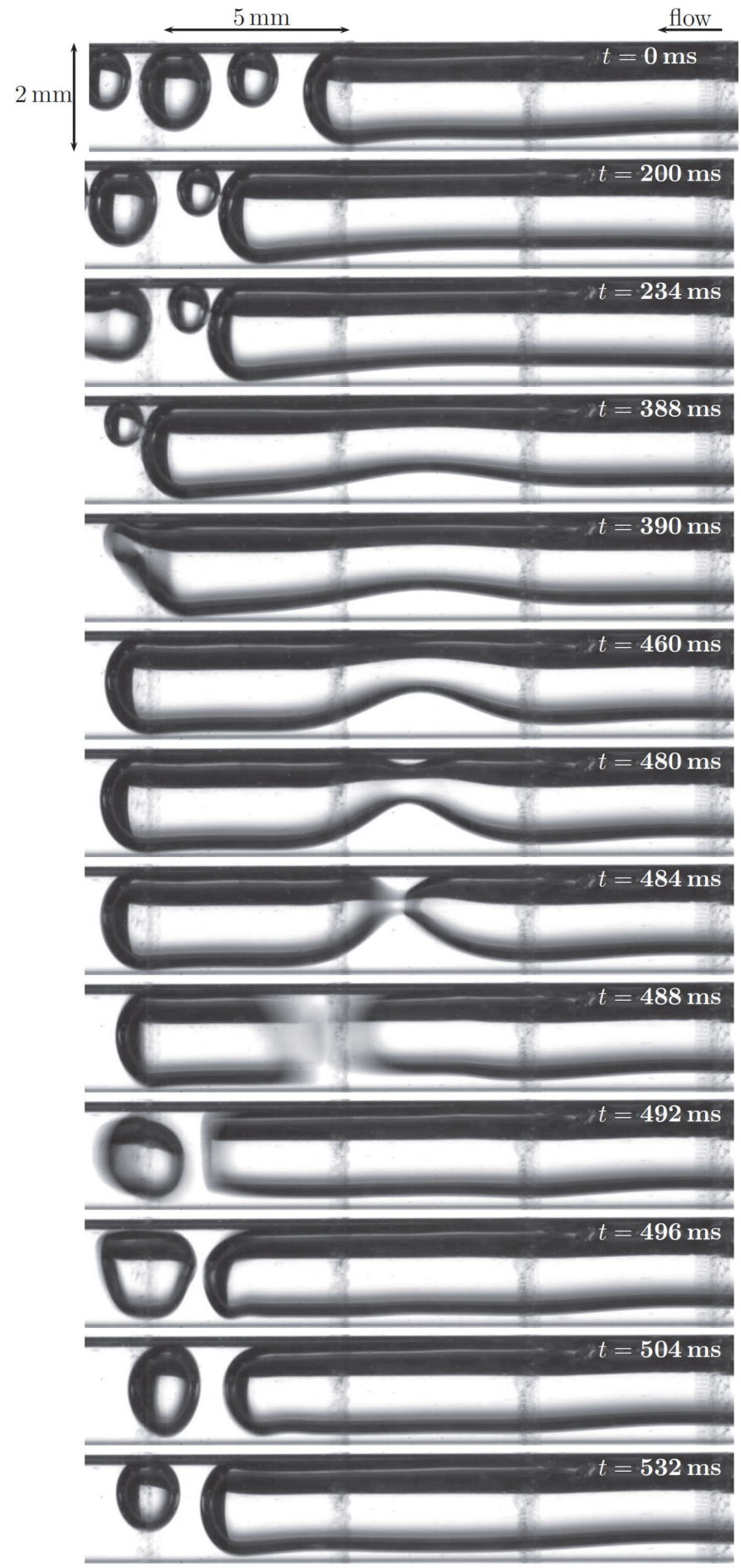

Fig 10 Bubble detachment in the condenser $-Q_{i n}=27 \mathrm{~W}, T_{\sin k}=10^{\circ} \mathrm{C}$

In the present investigation, droplets start to form on the internal surface of the tube. As condensation continues, the droplets grow and coalesce to form larger drops. This mechanism is quite slow because heat transfer to the ambient is moderate. When the coalescence of the drops leads to the formation of a liquid slug, vapour cannot circulate in the 


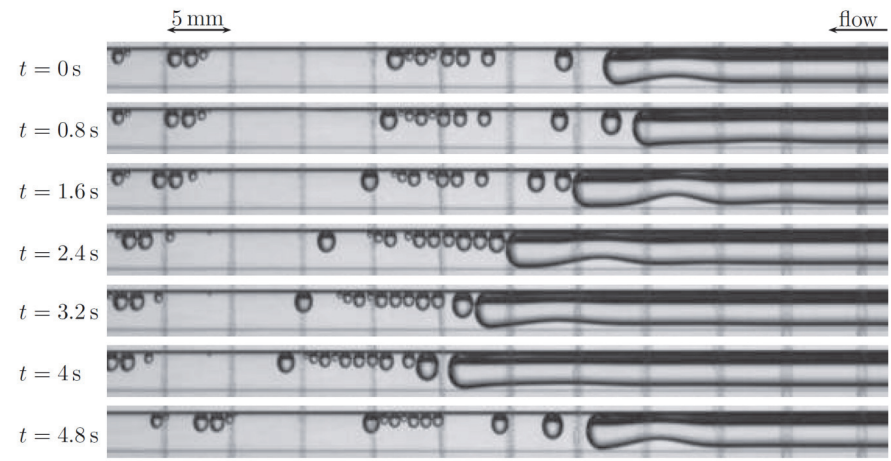

Fig 11 Location of the meniscus in the condenser $Q_{i n}=24 \mathrm{~W}, T_{\operatorname{sink}}=$ $10{ }^{\circ} \mathrm{C}$
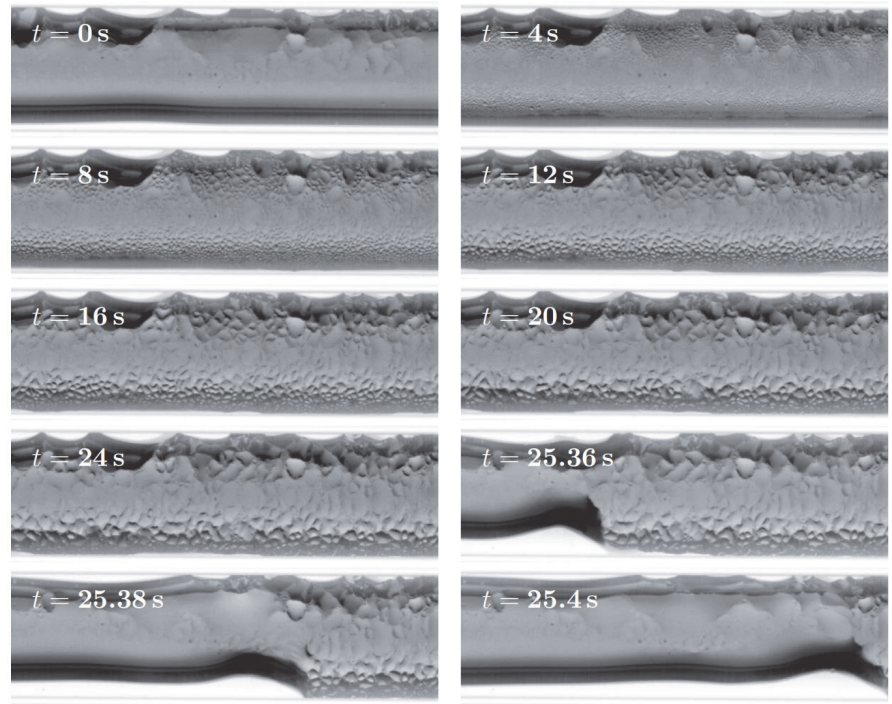

Fig 12 Drop-wise condensation in the vapour line $-Q_{i n}=27 \mathrm{~W}, T_{\text {sink }}=$ $10{ }^{\circ} \mathrm{C}$

central part of the tube and pushes the liquid slug downstream, thus carrying away the condensed liquid on the internal surface $(t=25.4 \mathrm{~s})$. In the upper side of the tube, several larger drops remain unchanged during the entire process and are not necessarily disturbed by the sudden liquid flow.

The drop-wise condensation and the intermittent liquid flow associated to it are the source of temperature oscillations in the vapour line and in the rest of the system at low heat loads, as it was further discussed in section 4.

\section{CONCLUSIONS}

In this work, the design of an experimental LHP, developed for research purposes is presented. Pressure and temperature measurements enable to characterise the operation of the LHP, as well as direct observations of the hydrodynamic phenomena thanks to the use of glass for the transport lines and the condenser and of a window glass for the reservoir. The hysteresis and temperature oscillation phenomena of this LHP are investigated. The obtained results are useful to understand the behaviour of the system:

- A temperature hysteresis is observed between increasing and decreasing heat loads. Temperature differences of about $8 \mathrm{~K}$ at $40-45 \mathrm{~W}$, at the evaporator wall, and $7 \mathrm{~K}$ at $15-20 \mathrm{~W}$, in the vapour line, are recorded for a 150 mbars partial pressure of NCGs. The main explanation of this hysteresis is a partial dry-out of the capillary structure. A change of the ambient temperature or a potential increase of NCGs during the test of the system can increase this effect.
- At moderate and high heat fluxes, boiling occurs inside the reservoir, inducing a sharp degradation of the system performance and a significant increase of the hysteresis. The nucleation in the reservoir is a complex phenomenon depending on various parameters and cannot be accurately predicted.

- The effect of non-condensable gases is also evaluated from 0 to 150 mbars. NCGs induce an additional pressure in the reservoir and thus larger parasitic heat fluxes and a higher operating temperature. If the saturation temperature is equal to $45^{\circ} \mathrm{C}$, a partial pressure of the NCGs of 30 mbars leads to an additional superheat of $5.4 \mathrm{~K}$. They also have a major influence on the boiling incipience in the reservoir, delaying the nucleation process.

- Temperature oscillations are observed at very low heat loads $(5 \mathrm{~W})$, for $T_{\text {sink }}=T_{a m b}$ and at moderate heat loads $(20 \mathrm{~W})$ and $T_{\text {sink }}-T_{a m b} \sim 10 \mathrm{~K}$. They are strongly coupled with the hydrodynamics in the transport lines. Indeed, the condensation regime in the vapour line and the variation of the meniscus location during operation induce periodical variations of the main temperatures of the LHP.

- Observations of the condensation phenomena inside the tubes confirm previous investigations from the literature. Three regions can be distinguished at the end of the two-phase zone in the condenser: an annular zone with a quasi-hemispherical meniscus, a train of bubbles and isolated bubbles in the liquid phase. The detachment of Taylor bubbles occurs with a fast and large deformation of the liquid vapour interface in the tube, inducing significant movements of liquid and vapour. The occurrence of drop-wise condensation in the vapour line leads to oscillating phenomena.

\section{NOMENCLATURE}

$\begin{array}{ll}g & \text { gravitational acceleration }\left(\mathrm{m} \cdot \mathrm{s}^{-2}\right) \\ L & \text { length }(\mathrm{m}) \\ P & \text { pressure }\left(\mathrm{N} \cdot \mathrm{m}^{-2}\right) \\ Q & \text { heat transfer rate }(\mathrm{W}) \\ t & \text { time }(\mathrm{s}) \\ T & \text { temperature }(\mathrm{K})\end{array}$

Greek Symbols $\begin{array}{ll}\rho & \text { density }\left(\mathrm{kg} \cdot \mathrm{m}^{-3}\right) \\ \sigma & \text { surface tension }\left(\mathrm{N} \cdot \mathrm{m}^{-1}\right)\end{array}$

$\begin{array}{ll}\text { Subscripts } & \\ \text { amb } & \text { ambient } \\ c & \text { condenser } \\ \text { cap } & \text { capillary } \\ e & \text { evaporator } \\ \text { ext } & \text { ambient } \\ i & \text { inlet } \\ \text { in } & \text { input } \\ l & \text { liquid } \\ \text { nuc } & \text { nucleation } \\ \text { NCG } & \text { non-condensable gases } \\ o & \text { outlet } \\ r & \text { reservoir } \\ \text { sink } & \text { heat sink } \\ \text { sat } & \text { saturation } \\ \text { static } & \text { static } \\ v & \text { vapour }\end{array}$

\section{REFERENCES}

Bernardin, J.D., Mudawar, I., Walsh, C. B., and Franses, E.I., 1997, "Contact angle temperature dependence for water droplets on practical aluminum surfaces," International journal of heat and mass transfer, 40(5), 1017-1033.

http://dx.doi.org/10.1016/0017-9310(96)00184-6 
Bartuli, E., Vershinin, S. and Maydanik, Yu., 2013, "Visual and instrumental investigations of a copper water loop heat pipe," International Journal of Heat and Mass Transfer, 61, 35-40. http://dx.doi.org/10.1016/j.ijheatmasstransfer.2013.01.074

Birdi, K.S., Vu, D.T., and Winter, A. 1989, "A study of the evaporation rates of small water drops placed on a solid surface," Journal of physical chemistry, 93(9), 3702-3703.

http://dx.doi.org/10.1021/j100346a065

Carey, V.P., 1992, Liquid-vapor phase-change phenomena. Hemisphere, New York

Cheung, K. H., Hoang, T., Ku, J., and Kaya, T., 1998, "Thermal performance and operational characteristics of loop heat pipe (NRL LHP)," SAE paper 981813.

Collier, J.G. and Thome, J.R., 1994, Convective boiling and condensation, 3rd ed., Oxford University Press, Oxford.

D'Entremont, B.P. and Ochterbeck, J. M., 2009, "Investigation of loop heat pipe start-up using liquid core visualization". Proceedings of the ASME Heat Transfer Conference, 2, 387-393.

El Achkar, G., Lavieille, P., and Miscevic, M., 2012, "Loop heat pipe and capillary pumped loop design: About heat transfer in the isolated bubbles zone of condensers," Applied Thermal Engineering, 33-34, 253257.

http://dx.doi.org/10.1016/j.applthermaleng.2011.09.011

He, J., Lin, G., Bai, L., Miao, J., Zhang, H., and Wang, L., 2013, "Effect of non-condensable gas on start-up of a loop thermosyphon," International Journal of Thermal Sciences, 72, 184-194.

http://dx.doi.org/10.1016/j.ijthermalsci.2013.05.009

Kaled, A., 2013, Etude expérimentale et théorique d'une boucle diphasique à pompage thermocapillaire dans le contexte de l'aéronautique. $\mathrm{PhD}$ thesis, Université de Toulouse.

Ku, J., 1999, "Operating characteristics of loop heat pipes," Proceedings of the 29th International Conference on Environmental System, Denver, Colorado, USA.

Launay, S. and Mekni, N., 2010, "Specifically designed loop heat pipe for quantitative characterization," Proceedings of the $15^{\text {th }}$ International Heat Pipe Conference, Clemson, USA.

Launay, S. and Vallée, M., 2011, "State-of-the-art experimental studies on loop heat pipes," Frontiers in Heat Pipes, 2, 013003, http://dx.doi.org/10.5098/fhp.v2.1.3003.
Louahlia-Gualous, H. and Mecheri, B., 2007, "Unsteady steam condensation flow patterns inside a miniature tube," Applied Thermal Engineering, 27(8-9), 1225-1235.

http://dx.doi.org/10.1016/j.applthermaleng.2006.10.033

Louriou, C., 2010, Modélisation instationnaire des transferts de masse et de chaleur au sein des évaporateurs capillaires. $\mathrm{PhD}$ thesis, Institut National Polytechnique de Toulouse.

Médéric, B., Miscevic, M., Platel, V., Lavieille, P., and Joly, J.-L., 2004, "Experimental study of flow characteristics during condensation in narrow channels: the influence of the diameter channel on structure patterns," Superlattices and Microstructures, 35(3-6), 573-586. http://dx.doi.org/10.1016/j.spmi.2003.11.008

Médéric, B., Lavieille, P., and Miscevic, M., 2005, "Void fraction invariance properties of condensation flow inside a capillary glass tube," International Journal of Multiphase Flow, 31(9), 1049-1058. http://dx.doi.org/10.1016/j.ijmultiphaseflow.2005.06.004

Mottet, L., Coquard, T. and Prat, M., 2015, "Three dimensional liquid and vapour distribution in the wick of capillary evaporators," International Journal of Heat and Mass Transfer, 83, 636-651. http://dx.doi.org/10.1016/i.ijheatmasstransfer.2014.12.048

Rainey, K.N., You, S. M., and Lee, S., 2003, "Effect of pressure, subcooling, and dissolved gas on pool boiling heat transfer from microporous, square pin-finned surfaces in FC-72". International Journal of Heat and Mass Transfer, 46(1), 23-35. http://dx.doi.org/10.1016/S0017-9310(02)00257-0

Siedel, B., Sartre, V., Lefèvre, F., 2013, "Numerical investigation of the thermohydraulic behaviour of a complete loop heat pipe," Applied Thermal Engineering, 61, 541-553.

http://dx.doi.org/10.1016/j.applthermaleng.2013.08.017

Siedel, B., Sartre, V., Lefèvre, F., 2015a, "Literature review: Steady-state modelling of loop heat pipes," Applied Thermal Engineering, 75, 709723.

http://dx.doi.org/10.1016/j.applthermaleng.2014.10.030

Siedel, B., Sartre, V., Lefèvre, F., 2015b, "Complete analytical model of a loop heat pipe with a flat evaporator", International Journal of Thermal Sciences, 89, 372-386.

http://dx.doi.org/10.1016/j.ijthermalsci.2014.11.014

Vershinin, S.V. and Maydanik, Y.F., 2007, "Hysteresis phenomena in loop heat pipes," Applied Thermal Engineering, 27(5-6), 962-968. http://dx.doi.org/10.1016/j.applthermaleng.2006.08.016

Wolf, D. A. and Bienert, W. B., 1994, "Investigation of temperature control characteristics of loop heat pipes," SAE paper 941576. 